\title{
Use of Triamcinolone Acetonide in External Dacryocystorhinostomy
}

\author{
Qirat Qurban ${ }^{1}$, Zeeshan Kamil ${ }^{2}$, Khalid Mehmood ${ }^{3}$ \\ ${ }^{1-3}$ Khalid Eye Clinic, Nazimabad, Karachi
}

\begin{abstract}
Purpose: To study the effect of Triamcinolone Acetonide injection into the ostium through the external wound after one week of external Dacryocystorhinostomy.
\end{abstract}

Study Design: Quasi experimental study.

Place and Duration of Study: Khalid Eye Clinic, Karachi, from July 2018 to June 2019.

Methods: This study included forty patients with age ranging between 18 to 36 years. All patients had obstruction of the nasolacrimal duct. Patients were categorized into two groups. Both groups underwent external dacryocystorhinostomy with silicone intubation, with the difference being that patients in group A were injected with 20 units of Triamcinolone acetonide $40 \mathrm{mg} / \mathrm{ml}$ into the ostium through wound using 27 gauge needle, one week after the surgery. Group B did not receive any injection. Both groups were followed for a period of four months, at which time the silicone tube was removed and patency of lacrimal system was ascertained via syringing with balanced salt solution through the lacrimal puncta. Main outcome measure was the success rate of procedure.

Results: The mean age of the patients was $27.1 \pm 5.48$ years. Success rate was $100 \%$ among the patients of group $A$ and $85 \%$ in the patients of group B at the end of the four months followup period. However, the results were statistically insignificant $(p=0.115)$.

Conclusion: Although statistically insignificant but clinically Triamcinolone Acetonide proved helpful in reducing fibrosis and ostium granuloma formation in patients with Ex-DCR. Thus preventing failure of external Dacryocystorhinostomy.

Key Words: Triamcinolone acetonide, external dacryocystorhinostomy, DCR.

How to Cite this Article: Qurban Q, Kamil Z, Mehmood K. Use of Triamcinolone Acetonide in External Dacryocystorhinostomy. Pak J Ophthalmol. 2022, 38 (1): 63-66.

Doi: $10.36351 /$ pjo.v38i1.1094

\section{INTRODUCTION}

Obstruction of the nasolacrimal duct is one of the commonest causes of watery eyes and discharge from

Correspondence: Qirat Qurban

Khalid Eye Clinic, Nazimabad, Karachi

Email:qirat_89@hotmail.com

Received: July 06, 2021

Accepted: December 12, 2021 the lacrimal sac. Surgical management of this disorder includes External Dacryocystorhinostomy (Ex DCR), which is performed by making a skin incision, removing the lacrimal bone, amalgamation of the sac mucosa to the nasal mucosa, followed by intubation with silicone tube, forming a functional passage via the lacrimal sac to the nasal cavity and increasing drainage of the tears in order to relieve watering and improve patient's distress. ${ }^{1}$ It was first introduced by Toti in 1904 to allow passage of tears straight into the nasal cavity from the canaliculi through an innovative low-resistance conduit. ${ }^{2}$ Ex DCR is a cost effective, 
gold standard procedure in patients with obstruction of the nasolacrimal duct with a success rate of $>90 \%$ depending upon the surgeon's experience. ${ }^{3}$ However, the success of Ex DCR is difficult to monitor due to lack of standardization of outcome.

Numerous factors have been discussed which may have an effect on the success rate of Ex DCR, such as incision shape, nasal mucosal flaps design, use of Mitomycin C (MMC) as an adjunct and use of intubation made of different materials. ${ }^{4-6}$ Use of intra operative and post operative corticosteroids have beenrecognized to curtailswelling and fibroblast recruitment and diminish scar configuration and resulting in a greater success rate. ${ }^{7,8}$

This study was done to find out the effect of postoperative injection of Triamcinolone Acetonide into the ostium through the external wound after one week of Dacryocystorhinostomy. The idea was to suppress fibrosis and granulation tissue formation which are responsible for occlusion of the osteotomy site. This will reduce the failure rate.

\section{METHODS}

This study was conducted at Khalid Eye Clinic, Karachi, from July 2018 to June 2019 and included forty patients with ages ranging between 18 to 36 years. All patients had nasolacrimal duct obstruction (NLDO). All patients underwent a thorough ocular assessment prior to the surgery. Probing and syringing of the lacrimal drainage system was performed in all the patients to identify the obstruction of nasolacrimal duct and to exclude the canalicular block. Patients with one-sided or two - sided obstruction of the nasolacrimal duct (as assessed by irrigation of the nasolacrimal duct), ages between 18 to 36 years, absence of lid or eyelash abnormality and willingness to follow-up for at least 4 months were included in this study. Patients with obstruction of the superior or inferior or common canaliculus were excluded from the study. Informed verbal consent was obtained and institutional ethical review board approval was taken. Patients were randomly divided into two groups and both groups underwent standard external dacryocystorhinostomy with silicone intubation. Patients in group A were injected with 20 units of Triamcinolone acetonide $40 \mathrm{mg} / \mathrm{ml}$ into the ostium via operative site using 27 gauge needle one week after the surgery. Group B patients did not receive any injection. Both groups were followed for a period of four months, at which time the silicone tube was removed and patency of lacrimal system was ascertained via syringing with balanced salt solution through the lacrimal puncta. Main outcome measure was the success rate of procedure assessed by improvement in symptoms (no epiphora) and open DCR fistula checked by syringing at four months post surgery. Data was analyzed on SPSS version 25.

\section{RESULTS}

This study included forty patients of age group between 18 to 36 years and divided into two groups. The mean age was $27.1 \pm 5.48$ years. There were 32 (80\%) females and $8(20 \%)$ males. Right eye was involved in $18(45 \%)$ cases and left eye in $22(55 \%)$ patients. At the end of four months follow-up, patency of lacrimal system via syringing with balanced salt solution was confirmed in all 20 patients $(100 \%)$ of group A, whereas 17 out of 20 patients $(85 \%)$ of group $\mathrm{B}$ had a patent lacrimal drainage system. P-value (0.115 by Fisher exact test) was not significant. Group A patients receiving Triamcinolone acetonide injection were of concern to the authors due to steroid related local complications but none of patients of group A reported any complication such as wound infection, wound dehiscence, surrounding fat atrophy or skin depigmentation. Mean followup period was $136.6 \pm$ 12.78 days.

\section{DISCUSSION}

External Dacryocystorhinostomy (Ex DCR), despite a very commonly performed procedure sometimes leads to failure. It occurs due to blockage of ostium caused by granulation tissue, scarring and formation of adhesions in the nasal cavity with subsequent signs of disproportionate watering post operatively. It results in failure to drain the tears. ${ }^{9,10}$ Previous studies have shown that patients who underwent subsequent operation, had a thick scar tissue at the osteotomy site. ${ }^{11}$ Similarly, it is also reported that the reason of failure of Dacryocystorhinostomy was blockage of the drainage conduit by an occluding film composed of organized granulation tissue. ${ }^{12}$ Thus, reducing fibrous tissue formation at the osteotomy site and the anastomosed flapscan enhance thesuccess of Ex DCR.

Various procedures and adjunctive have been studied to improve the success rate of Ex DCR. ${ }^{13,14} \mathrm{~A}$ synthetic corticosteroid, Triamcinolone acetonide 
(TA), had been used to treat orbital diseases such as thyroid ophthalmopathy, capillary hemangioma of the orbit and idiopathic inflammation of the orbitin the precedent decade. $^{15,16}$

Studies have demonstrated a significant independent association with failure in revision external DCR. Inadequate ostium size was the most common cause of failure in primary external, endonasal, and laser DCR. Canalicular or common canalicular obstruction, intranasal pathology, and bilateral lacrimal obstruction were significant predictors of failure in revision external DCR. ${ }^{17}$ Another researcher used Triamcinolone Acetonide (TA) soaked gelfoam in DCR nasal septoplasty with a success rate of $96.4 \% .^{18}$ Ninety three percent success rate was reported in another case series using intraoperative TA in endonasal endoscopic DCR. ${ }^{19}$ This study observed a $100 \%$ success rate following the injection of TA in Group A patients. Factors responsible for failure of DCR are improper positioning of the Rhinostomy, insufficient sac aperture and fibrosis at the ostium. ${ }^{20}$ Therefore, a good anatomical knowledge is required along with a careful surgery by a skilled surgeon to maximize the success rate.

Following Ex DCR, healing occurs in three steps; inflammation phase, proliferation phase and maturation phase. ${ }^{10}$ In this study, we used TA after one week of Ex DCR to prevent swelling in the earlystage of wound healing and todecrease the proliferative stage of healing. Another study described the use of TA and at the end of the follow-up period of six months, did not report any corticosteroid associated adverse effects such as rise of intraocular pressure, mucosal thinning, skinpigment abnormality or fat wasting. ${ }^{15}$ This was in accordance to our study.

Every study has a different parameter for the definition of DCR success. Therefore, it is tricky to weigh against printed accomplishment rates of DCR. In this study, the success of Ex DCR surgery was assessed on the basis of improvement of symptoms such as no watering and open lacrimal passageway on syringing at four months post surgery.

Limitations of this study were less number of patients in the study, single center study and four months followup. Further long term followup needs to be done to find out the effectiveness of this technique.

\section{CONCLUSION}

Triamcinolone Acetonide injection after one week of Ex DCR surgery, proved to be safe and successful in reducing fibrosis and ostium granuloma formation with improvement of watering and anatomical patency of inner ostia. Although the results were not statistically significant but clinically this technique was helpful in preventing failure of external Dacryocystorhinostomy. No major complications associated with Triamcinolone Acetonide injection were encountered.

\section{Ethical Approval}

The study was approved by the Institutional review board/Ethical review board (ERC-18-20).

\section{Conflict of Interest}

Authors declared no conflict of interest.

\section{REFERENCES}

1. Ali MJ, Naik MN, Honavar SG. External dacryocystorhinostomy: Tips and tricks. Oman J Ophthalmol. 2012; 5 (3): 191-195. doi:10.4103/0974620X.106106

2. Toti A. Endoscopic endonasal dacryocystorhinostomy: our experience Clin Moderna Firenze. 1904; 10: 385387.

3. Walland MJ, Rose GE. Factors affecting the success rate of open lacrimal surgery. Br J Ophthalmol. 1994; 78: $888-891$

4. Erdöl H, Akyol N, Imamoglu HI, Sözen E. Longterm follow-up of external dacryocystorhinostomy and the factors affecting its success. Orbit. 2005; 24 (2): 99-102.

5. Pandya VB, Lee S, Benger R, Danks JJ, Kourt G, Martin PA, et al., External dacryocystorhinostomy: assessing factors that influence outcome. Orbit. 2010; 29 (5): 291-297.

6. Seider N, Kaplan N, Gilboa M, Gdal-On M, Miller B, Beiran I. Effect of timing of external dacryocystorhinostomy on surgical outcome. Ophthalmic Plast Reconstruct Surg. 2007; 23 (3): 183186.

7. Waly MA, Shalaby OE, Elbakary MA, Hashish AA. The cosmetic outcome of external dacryocystorhinostomy scar and factors affecting it. Indian J Ophthalmol. 2016; 64 (4): 261-265. doi:10.4103/0301-4738.182933

8. Naik VN, Kumar V. Intraoperative Injection of Triamcinolone Acetonide in External Dacryocystorhinostomy. Int $\mathrm{J}$ Ophthalmol Eye Res. 2020; 8 (2): 424-428.

Doi: http://dx.doi.org/10.19070/2332-290X-2000086 
9. Ali MJ, Wormald PJ, Psaltis AJ. The dacryocystorhinostomy ostium granulomas: classification, indications for treatment, management modalities and outcomes. Orbit. 2015; 34: 146-151.

10. Allen K, Berlin AJ. Dacryocystorhinostomy failure: association with nasolacrimal silicone intubation. Ophthalmic Surg. 1989; 20: 115-119.

11. Deka A, Bhattacharjee K, Bhuyan SK, Barua CK, Bhattacharjee $\mathbf{H}$, Khaund G. Effect of mitomycin $\mathrm{C}$ on ostium in dacryocystorhinostomy. ClinExp Ophthalmol. 2006; 34 (6): 557-561.

12. Harish V, Benger RS. Origins of lacrimal surgery, and evolution of dacryocystorhinostomy to the present. Clin Exp Ophthalmol. 2014; 42 (3): 284-287.

Doi: 10.1111/ceo.12161. Epub 2013 Aug 4. PMID: 23845081 .

13. Kühnel T. Erkennung und Vermeidung von Schwierigkeitenbei der Tränenwegschirurgie [Recognition and prevention of problems in lacrimal duct surgery]. HNO. 2018; 66 (6): 432-437. German. Doi: 10.1007/s00106-018-0507-4. PMID: 29761204.

14. Roozitalab MH, Amirahmadi M, Namazi MR. Results of the application of intraoperative mitomycin C in dacryocystorhinostomy. Eur J Ophthalmol. 2004; 14: 461-463.

15. Leibovitch I, Prabhakaran VC, Davis G, Selva D. Intraorbital injection of triamcinolone acetonide in patients with idiopathic orbital inflammation. Arch Ophthalmol. 2007; 125: 1647-1651.

16. Ebner R, Devoto MH, Weil D, Bordaberry M, Mir C, Martinez H, et al. Treatment of thyroid associated ophthalmopathy with periocular injections of triamcinolone. Br J Ophthalmol. 2004; 88 (11): 13801386.

Doi: 10.1136/bjo.2004.046193. PMID: 15489477; PMCID: PMC1772392.

17. Meryem EA, Seyda KU, Hasan A, Sevinc SA. Failure in Revision Dacryocystorhinostomy: A Study of Surgical Technique and Etiology. J Craniofac Surg. 2020; 31 (1): 193-196.

Doi: $10.1097 /$ SCS.0000000000005829
18. Kang TS, Won YK, Kim JY, Kim KN, Lee SB. Efficacy of Triamcinolone-Soaked Nasal Packing on Endoscopic Dacryocystorhinostomy. Ophthalmic Plast Reconstr Surg. 2021; 37 (3S): S44-S47.

Doi: 10.1097/IOP.0000000000001791.

PMID: 32773515.

19. Li EY, Cheng AC, Wong AC, Sze AM, Yuen HK. Safety and efficacy of adjunctive intranasal mitomycin $\mathrm{C}$ and triamcinolone in endonasal endoscopic dacryocystorhinostomy. Int Ophthalmol. 2016; 36 (1): 105-110. Doi: 10.1007/s10792-015-0088-0. Epub 2015 May 26. PMID: 26003991.

20. Ghasemi H, AsghariAsl S, Yarmohammadi ME, Jafari F, Izadi P. External Dacryocystorhinostomy; Success Rate and Causes of Failure in Endoscopic and Pathologic Evaluations. Iran J Pathol. Summer, 2017; 12 (3): 189-194. Epub 2017 Jul 1. PMID: 29531542; PMCID: PMC5835365.

\section{Authors' Designation and Contribution \\ Qirat Qurban; Consultant Ophthalmologist: Concepts, Design, Literature Search, Data Analysis, Statistical Analysis, Manuscript Preparation, Manuscript Editing. \\ Zeeshan Kamil; Consultant Ophthalmologist: Concepts, Design, Literature Search, Data Analysis, Statistical Analysis, Manuscript Preparation, Manuscript Editing.}

Khalid Mehmood; Consultant Ophthalmologist: Data Acquisition, Manuscript Review. 